\title{
Relations among regular and irregular morphologically related words in the lexicon as revealed by repetition priming
}

\author{
CAROL A. FOWLER \\ Dartmouth College, Hanover, New Hampshire \\ and Haskins Laboratories, New Haven, Connecticut \\ SHIRLEY E. NAPPS \\ Dartmouth College, Hanover, New Hampshire \\ and \\ LAURIE FELDMAN \\ University of Delaware, Newark, Delaware \\ and Haskins Laboratories, New Haven, Connecticut
}

\begin{abstract}
Several experiments examined repetition priming among morphologically related words as a tool to study lexical organization. The first experiment replicated a finding by Stanners, Neiser, Hernon, and Hall (Journal of Verbal Learning and Verbal Behavior, 1979, 18, 399-412), that whereas inflected words prime their unaffixed morphological relatives as effectively as do the unaffixed forms themselves, derived words are effective, but weaker, primes. The experiment also suggested, however, that this difference in priming may have an episodic origin relating to the less formal similarity of derived than of inflected words to unaffixed morphological relatives. A second experiment reduced episodic contributions to priming and found equally effective priming of unaffixed words by themselves, by inflected relatives, and by derived relatives. Two additional experiments found strong priming among relatives sharing the spelling and pronunciation of the unaffixed stem morpheme, sharing spelling alone, or sharing neither formal property exactly. Overall, results with auditory and visual presentations were similar. Interpretations that repetition priming reflects either repeated access to a common lexical entry or associative semantic priming are both rejected in favor of a lexical organization in which components of a word (e.g., a stem morpheme) may be shared among distinct words without the words themselves, in any sense, sharing a "lexical entry."
\end{abstract}

Words presented for lexical decision are more rapidly classified, and words presented under poor viewing or listening conditions are more readily reported, if they have been presented previously in the experimental setting than if they have not (e.g., Forbach, Stanners, \& Hochhaus, 1974; Murrell \& Morton, 1974; Scarborough, Cortese, \& Scarborough, 1977). We will refer to this general outcome as "repetition priming." Morton (e.g., 1981) and Stanners, Neiser, Hernon, and Hall (1979) have interpreted repetition priming as a consequence of repeated access to a lexical entry. Other research has identified both episodic (Feustil, Shiffrin, \& Salasoo, 1983; Jacoby \& Dallas, 1981) and strategic (Forster \& Davis, 1984; Oliphant, 1983) components to the priming effect as well.

This research was supported by NIH Grant HD 01994 to Haskins Laboratories. We thank Vicki Hanson and George Wolford for their comments on the manuscript.

C. A. Fowler's mailing address is: Department of Psychology, Dartmouth College, Hanover, NH 03755.
The lexical interpretation is of particular interest in light of patterns of priming that are observed among morphologically related words. Priming may occur in two forms that we refer to as "full" and "partial." Full priming is priming of one word by another that is as large, statistically, as priming of a word by itself. Partial priming is priming of one word by another that is present, statistically, but is significantly less than priming of a word by itself. Generally, the findings are that priming of a base word by regularly inflected morphological relatives is full, whereas priming by derived forms is partial (Stanners et al., 1979). Priming by irregularly affixed words may be partial (Stanners et al., 1979) or absent (Kempley \& Morton, 1982).

Stanners et al. (1979) interpret full priming as evidence that stem forms and inflected relatives share a lexical entry; they interpret partial priming as evidence that stem forms and derived words are neighbors in the lexicon. This pattern of priming and its interpretation are appealing in supporting plausible roles for lexical entries in language use. One role has repetition priming as a by- 
product; a second role gives repetition priming its patterning.

In Morton's $(1969,1981)$ theory of the lexicon, lexical entries are "logogens," which collect evidence for the occurrence in stimulation of the words they represent. Sufficient evidence, enough to exceed a logogen's threshold, causes the logogen to "fire." As one consequence of firing, the threshold is lowered temporarily so that less evidence is necessary for firing if the word is presented a second time. The threshold rises very slowly over time. Thresholds of frequent words are kept permanently lowered by the frequent recurrence of the words in stimulation. The frequency-sensitive thresholds of logogens explain repetition priming, but more usefully for language users, they prepare language users for perception of words most likely to occur in the environment. In this first role, repetition priming is a by-product of the normal operation of the logogen system.

Arguably, this mechanism would work well if, as the repetition priming data suggest, the lexicon counted a stem morpheme and its regularly inflected, but not derived, forms as the same word. Unaffixed words and their inflected relatives are the same part of speech with essentially the same core meaning; in a sense, they are the same words, with the difference between them determined by the grammatical context in which they appear. Consequently, a common frequency-based expectancy is meaningful for classes of words differing only in inflectional affix. In contrast, unaffixed words and their derived relatives often are not the same part of speech and need not be close in meaning (see Aronoff, 1976); consequently, a common frequency-based expectancy for unaffixed words and their derived relatives would not be meaningful.

The second role for a lexical entry may be to provide appropriate input to regular and productive phonological rules of language. In generative phonology (Chomsky \& Halle, 1968), a lexical entry includes just that phonological information about a word that is not predictable by rule, and hence that uniquely identifies a word. The phonological rules that are most productive and regular in English (and thus, perhaps, that are most likely to be learned by language users; see Berko, 1956; Ohala, 1974; Steinberg, 1973) are rules of inflection. The finding that inflected words prime their stems fully, then, is consistent with a lexicon in which inflected words have no independent representation. Certain speech errors (e.g., morpheme shifts and strandings; Garrett, 1980a, 1980b) have been interpreted as supporting a similar conclusion; so have the speech patterns of some Broca's and jargon aphasics (see Butterworth, 1983, for a review of the relevant evidence).

Despite the consistent and plausible view of the lexicon provided by repetition-priming findings, we decided, for two reasons, to investigate priming patterns further. The first reason was that repetition effects found in the memory literature (e.g., Light \& Carter-Sobell, 1970) are ascribed to episodic, not to lexical, memory, and episodic sources of priming are found using paradigms very similar to the repetition priming paradigms themselves (Feustil et al., 1983).

Moreover, it is not difficult to imagine how, using the procedures of Morton or of Stanners et al., episodic influences might contribute to priming. Subjects may explicitly recall having seen a word (or morphological relative) previously in the experiment, and, in the procedure of Stanners et al., they may recall the response they made to it. This recollection may facilitate responding to a primed word. These episodic sources of priming are unlikely to exhaust the repetition priming that occurs (Jacoby \& Dallas, 1981); however, added to lexical sources of priming, they are likely to exaggerate the apparent loss in priming of an unaffixed form by a derived form relative to its priming by an inflected form or by itself. This exaggerated difference would occur because derived forms generally are less formally or semantically similar to stem forms than are inflected forms (and, of course, than is a stem word to itself). Consequently, memory for a derived prime may be less likely to be cued during later presentation of the unaffixed word than would memory for an uninflected prime or for the target word itself. Accordingly, full priming between a word and itself or between a word and an inflected variant may include both lexical and episodic sources of priming, whereas partial priming, as between a derived prime and unaffixed target, may include only lexical sources of priming.

Our second reason to further explore the patterning of repetition priming was derived from questions raised about any repetition priming's having a lexical rather than an episodic origin. The main question was whether repetition priming originating in the lexicon always reflected repeated access to a common lexical entry. In a recent review of the literature on word recognition, speech errors, and the speech and reading patterns of various language-disabled populations, Butterworth (1983) disputed the conclusion that lexical entries were common to unaffixed words and their affixed relatives in English. Instead, in his view, the bulk of evidence supported separate, but associated, entries for all words. If this interpretation is correct, then repetition priming may occur between separate entries in the lexicon. Our research investigated the distinction between shared lexical entries for morphological relatives and associated, but separate, entries.

Our first experiment was designed to test for episodic sources of influence on repetition priming. After finding them, we took steps in later experiments to reduce or eliminate them and to reexamine the pattern of repetition priming among stems and regularly and irregularly inflected and derived morphological relatives. This patterning suggested hypotheses concerning the organization of morphologically related words in the lexicon.

\section{EXPERIMENT 1}

As an index of episodic priming, we chose to look at repetition priming on nonwords-both regular and irregu- 
lar. The literature does not offer a clear indication of whether nonword repetition priming should be found using a lexical-decision paradigm. Forbach, et al. (1974) report essentially no repetition priming among nonwords; however, Scarborough, et al. (1977) report some priming of this type. Stanners et al. (1979) do not report their findings on nonwords.

In Experiment 1, we examined repetition priming among words and nonwords under conditions replicating those in which Stanners et al. found full-repetition priming of base forms by inflected morphological relatives and partial priming by derived forms.

\section{Method}

Subjects. The subjects were 25 Dartmouth College undergraduates who participated in the experiment for course credit. All were native speakers of English and had normal or corrected vision.

Stimulus materials. The stimuli used in the experiment were 48 English words and 48 nonwords. The words formed two groups. One group (inflections only) was presented both in "base" form (without suffixes) and with inflectional suffixes "s" and "ed." The second group (derivations and inflections) appeared in base form, with the inflectional suffixes "s" and "ed," and with two derivational suffixes ("ment" and either "er"/"or" or "able"/"ible"). Thus, within the second group, the effects of inflectional and derivational forms of the same word could be compared with each other. Words were chosen so that suffixation did not change the spelling or pronunciation of the base.

Nonwords formed three groups. Items in the first group (nonword, inflections only) were created from real words with the same characteristics as the real words in the inflections-only group. To form the nonwords, one or two letters in the real words were changed. The resulting nonwords were orthographically regular. These were presented both in a base form and with inflectional suffixes. Thus, they were the nonword counterparts of the first group of real words. The second group (irregular, inflections only), consisted of 10 irregular four-letter constructions, and these were also presented both in base form and with inflectional suffixes " $s$ " and "ed." Irregular nonwords were included in the study to provide an index of episodic priming in nonwords presumed not to have any form of representation in the lexicon. The third group of nonwords (nonword derivations and inflections) were analogous to the second group of real words. They were orthographically regular and were presented in base form, with inflectional suffixes " $s$ " and "ed," and with the derivational suffixes "ment" and "er"/"or" or "able"/"ible." The words used in the experiment and the words from which the 38 regular nonwords were formed were equated on average length and on mean and median frequency (Kučra \& Francis, 1967). Real-word base forms are listed in Appendix A.

Five test orders were created, each one including the following priming conditions in equal numbers: (1) base as target with no prime (henceforth B1), (2) base as prime and base as target (BB; e.g.. "manage"." "manage"), (3) inflection as prime and base as target (IB; e.g. " "manages"'."manage"), and (4) derivation as prime and base as target (DB; e.g., "management"-."manage"). Across test orders, items appeared in identical serial positions, but the sequences differed in which version of each item served as a prime. For example, for the base word "manage," the forms "manage," "manages," "managed," "managernent," and "manager" served as primes in the different test sequences. In all sequences, the target was "manage." For items occurring only in base forms and inflections in the experiment, each inflected form (i.e., "s" or "ed") occurred in two test sequences as primes and the base form occurred in one as prime. Inflections, derivations, and base first occurrences were distributed proportionately over the five test sequences.
Subjects saw each morpheme only twice: once as a prime and once as a target. The average lag between the occurrence of a prime and the occurrence of its target was nine intervening trials; lags ranged from 6 to 12 , and each lag was equally frequent among words and nonwords. Filler items were used as necessary to maintain appropriate lags. Each subject completed five blocks of 56 trials each, the first of which was a block of practice trials. Primes and targets were presented within one block.

Design. Five subjects were assigned to each of the five test orders. The independent variables were priming condition and lexical status (word, nonword). The main dependent variable was response time.

Procedure. The subjects were run individually. The experiment was run on a time-sharing computer interfaced with a Polytronics response timer. The stimuli were presented in upper case on a cathode ray tube. On each trial, the following sequence of events occurred: (1) a fixation string of plus signs $(++++++++$ ) came on; (2) the terminal bell sounded $500 \mathrm{msec}$ before the fixation mark went off; (3) a letter-string appeared as soon as the fixation mark disappeared, and remained on until the subject responded; (4) once the subject responded and the stimulus disappeared, the fixation mark returned and another trial began.

For each subject, the " $K$ " key of the computer terminal was pressed with the right index finger for a word stimulus and the " $D$ " key with the left index finger for a nonword stimulus. The keys were labeled with the symbols " $W$ " and "NW" for "word" and "nonword," respectively. The subjects were informed that both accuracy and speed of responding were important, and that accuracy should be kept above $90 \%$ correct on each block of trials.

Between blocks of trials, the subjects were informed of their mean reaction times and proportions correct for the preceding block of trials. Blocks were initiated by the subject.

\section{Results $^{1}$}

Errors and extreme reaction times (greater than $2,000 \mathrm{msec}$ or more than $2.5 \mathrm{SDs}$ from the individual subject's or item's mean) were excluded from the analysis. This procedure excluded less than $1 \%$ of the responses. When a subject responded incorrectly to one member of a prime-target pair, both responses were excluded from the analyses. Table 1 presents mean response times and errors to base targets.

In all experiments, error rates are reported in the appropriate tables. Analyses on the error rates are reported only if they are significant.

One-way subject and item analyses were performed on response times to base words (Conditions B1, BB, IB, and DB). Separate analyses were done on the 32 items appearing only in inflected and base forms (inflections only) and on the 16 items appearing in derived, inflected,

Table 1

Mean Reaction Times for Words and Nonwords for the Various Prime-Target Conditions of Experiment 1

\begin{tabular}{lllll}
\hline & B1 & BB & IB & DB \\
\hline \multicolumn{4}{c}{ Words } \\
Inflections only & 602 & $516(.10)$ & $513(.12)$ & \\
Derivations and Inflections & 552 & $499(.01)$ & $506(.04)$ & $524(.07)$ \\
& Nonwords & & \\
Inflections only & 689 & $654(.09)$ & $648(.18)$ & \\
Irregular Inflections only & 625 & $551(0)$ & $585(.06)$ & \\
Derivations and Inflections & 691 & $615(.16)$ & $653(.13)$ & $675(.13)$
\end{tabular}

Note-Error rates are in parentheses. 
and base forms (derivations and inflections). For the inflections-only group of words, the effect of priming condition was significant [subjects, $\mathrm{F}(2,40)=17.90$, $\mathrm{p}<$ .001 ; items, $F(2,62)=20.09, p<.001]$. Scheffé's tests revealed that the significant main effect was due to the $\mathrm{B} 1$ condition's differing from the $\mathrm{BB}$ and IB conditions [subjects, $F(2,40)=13.8, p<.001$; items, $F(2,62)=$ $15.5, \mathrm{p}<.001]$. The difference between the BB and IB conditions was not significant.

An analogous analysis on the remaining 16 words revealed a similar outcome for inflections, but only a partial repetition effect for derivations. The main effect of priming condition was significant [subjects, $F(3,60)=$ $6.17, \mathrm{p}=.001$; items, $\mathrm{F}(3,45)=4.87, \mathrm{p}=.005]$. Scheffé's tests showed that this effect was again due to the $\mathrm{B} 1$ condition's differing from the $\mathrm{BB}$ and $\mathrm{IB}$ conditions [subjects, $F(3,60)=3.77, p=.015$; items, $F(3,45)$ $=3.62, \mathrm{p}=.02]$. The $\mathrm{BB}$ and IB conditions did not differ from each other. In the $\mathrm{DB}$ condition, the mean response time did not differ from either $\mathrm{B} 1$ response time or $\mathrm{BB}$ and IB response times. These results are very similar in pattern to those of Experiments 1 and 3 of Stanners et al. (1979).

Similar analyses were performed on nonwords. Separate analyses were done on response times to the regular nonwords appearing only in inflected and base forms, the 16 regular nonwords appearing as derivations, inflections, and bases, and the 10 irregular nonwords. The effect of priming condition was marginally significant for the nonword inflections-only group in the subject analysis only [subjects, $\mathrm{F}(2,40=2.96, \mathrm{p}=.06$; items, $\mathrm{F}(2,42)$ $=1.29, \mathrm{p}=.28 \mathrm{]}$. Priming was significant for nonwords in the nonword derivations and inflections in the subject analysis $[F(3,60)=5.55, p=.002]$, and marginally significant in the item analysis $[\mathrm{F}(3,45)=2.53, \mathrm{p}=.06]$. Scheffe's tests showed the significance of the former effect to be due to the difference between the B1 and BB conditions $[F(3,60)=4.95, p=.004]$. The irregular inflections-only group reached significance in both analyses [subjects, $\mathrm{F}(2,40)=7.24, \mathrm{p}=.002$; items, $\mathrm{F}(2,18)$ $=4.25, \mathrm{p}=.03]$. These effects were also attributable, as shown by Scheffé's tests, to the difference between the $\mathrm{B} 1$ and $\mathrm{BB}$ conditions [subjects, $\mathrm{F}(2,40)=7.17, \mathrm{p}=$ .002 ; items, $\mathrm{F}(2,18)=4.16, \mathrm{p}=.03]$.

\section{Discussion}

The real-word results of Experiment 1 replicate the results of Stanners et al. (1979). Significant repetition priming of targets occurred for both base and inflection primes; derivations also primed their bases, but only marginally. Stanners et al. interpreted the corresponding partial-repetition effect they found to signify that derivations (and irregular inflections) had separate lexical entries from their base forms.

The nonword results obtained in the present experiment weaken this explanation. Presumably, nonword repetition effects, particularly those among irregular nonwords, are largely episodic rather than lexical in origin. That is, they occur because subjects remember explicitly having seen the letter strings previously in the experiment, and, perhaps, having made a particular response to them. If episodic priming affects response time to nonwords, it may also contribute to repetition priming in words. ${ }^{2}$ If it does, then partial repetition effects may reflect decreased episodic priming; the less the target in a prime-target pair looks like the prime, the less it reminds the subject of the prime.

Considerations such as these led us to repeat this study with an attempt to reduce the effects of episodic memory on subject responses.

\section{EXPERIMENT 2}

In an effort to reduce episodic contributions to the repetition effect, we extended the lag between primes and targets of a base morpheme from an average of 9 items in Experiment 1 to 48 items in Experiments $2 \mathrm{~A}$ and 2B.

In addition, we instituted a control for unequal practice on primes and targets. Necessarily, the prime of a morpheme appears earlier in the test sequence than its target. Consequently, subjects are less practiced, on the average, when they respond to primes than when they respond to targets. Possibly, a practice effect, too, contributes to priming.

Any asymmetrical practice of this sort can be eliminated by a procedure first used by Forbach et al. (1974) (but not used subsequently by Stanners et al., 1979). In the control procedure, the test sequence of words is partitioned into blocks. In the first block of test trials, only fillers and primes of morphemes are presented. In the second block, primes from the first block are repeated as targets interleaved with a new set of primes. In subsequent blocks, except the last, new primes are interleaved with repetitions of primes (now targets) from the previous block. In the final block, targets are interleaved with fillers. For most analyses, data from the first and last blocks are eliminated. In this way, analyses are restricted to comparisons of responses to primes and targets made at comparable levels of practice. Across subjects, words are counterbalanced so that every morpheme occurs equally often in each block as both prime and target.

Two experiments were run using these changes in procedure. In Experiment $2 \mathrm{~A}$, primes were inflections and base forms. In Experiment 2B, primes were derivations and base forms.

\section{Method}

Subjects. Subjects were 72 students from the same pool as that used in Experiment 1. Thirty-six subjects participated in each of Experiments $2 \mathrm{~A}$ and $2 \mathrm{~B}$. This gave three replications of all of the test-order conditions in each experiment.

Stimulus materials: Experiment 2A. Stimuli were 48 words and 48 nonwords matched in length to that of the words. Each word, a verb, appeared as a prime in each of three forms: uninflected (base), inflected with "s," and inflected with "ed." An individual subject saw each morpheme only twice: once as a prime and once as a target. In every instance, inflected forms preserved both the 
spelling and the pronunciation of the base. Targets were invariably base forms. Real-word base forms appear in Appendix B.

Nonwords were 24 orthographically regular and 24 irregular nonwords. Each nonword appeared as a prime in three forms: uninflected, inflected with "s," and inflected with "ed." Targets of nonwords were invariably base forms.

Stimulus materials: Experiment 2B. Stimuli were 48 words and 48 nonwords matched to the words in length. Each word and each nonword appeared as a prime in each of three forms: unaffixed and affixed with two derivational affixes (two of the following: "'ment," "less," "er," "ly," "ness," "able," "ful' "). As in Experiment $2 \mathrm{~A}$, each subject saw a given morpheme only twice. All nonwords were orthographically regular. Real-word bases are listed in Appendix B.

Test orders. The test sequences consisted of one practice block and five test blocks, each $\mathbf{4 8}$ trials in length. For purposes of counterbalancing, the 96 letter strings in the test list were partitioned into four sets. Each set included 12 words and 12 nonwords (4 bases, 8 affixed items). A Latin square was used to order the sets into four different sequences. For example, the Latin square ordering 1-2-4-3 created a test sequence in which items in the first set constituted the primes of the first block and the target repetitions of the second block. Primes in Block 1 were interleaved with filler items. Items in Set 2 provided the primes in Block 2 of the test sequence and the target repetitions in Block 3. Items in Set 4 provided the primes in the third block and the target repetitions in the fourth block. Finally, items in Set 3 provided the primes of Block 4 and the target repetitions in the final block. In the last block, Set 3 items were interleaved with fillers. The ordering procedure created a lag of 48 items between the prime and target of a morpheme.

The four test orders, each based on one row of the Latin square, appeared in three versions. The versions were identical except for the affixes on their first-occurring morphemes. For example, if "pushes" appeared as a prime in Block 2 of a test order, this was matched by two test orders in which "push" and "pushed," respectively, appeared as primes in Block 2 . In each experiment, one third of the priming items were bases, one third were words affixed with " $s$ " in Experiment $2 \mathrm{~A}$ and one of the derivational affixes in Experiment $2 \mathrm{~B}$, and the remaining third included words affixed with "ed" in Experiment $2 \mathrm{~A}$ and words with other derivational affixes in Experiment 2B. This gave 12 different test orders for each of Experiments $2 \mathrm{~A}$ and $2 \mathrm{~B}$.

Design. Subjects experienced all levels of the independent variable, priming condition. The primary dependent measure was response time.

Procedure. The procedure was identical to that followed in Experiment 1 .

\section{Results}

Response times and errors were analyzed as in Experiment 1 . Table 2 presents response times and errors to base words and nonwords in blocks 2-4 from Experiments 2A and $2 B$.

Table 2

Response Times to Words and Nonwords in Experiments 2A (Left) and 2B (Right)

\begin{tabular}{cccccc}
\hline B1 & BB & IB & B1 & BB & DB \\
\hline 611 & $510(.07)$ & $533(.07)$ & 585 & $543(.05)$ & $538(.03)$ \\
& \multicolumn{6}{c}{ Wonwords } \\
643 & $627(.14)$ & $645(.10)$ & 715 & $717(.17)$ & $730(.16)$ \\
\hline
\end{tabular}

Note-Error rates are in parentheses.
Response times to base words in Experiment 2A differ as a function of their priming condition [subject analysis, $\mathrm{F}(2,70)=54.73, \mathrm{p}<.001$; item analysis, $\mathrm{F}(2,94)=$ $46.59, p<.001]$. Scheffé's tests reveal no significant difference on the subjects analysis in response times to $\mathrm{BB}$ and $\mathrm{IB}$ words $[\mathrm{F}(2,70)=2.56, \mathrm{p}=.08]$. However, the difference does reach significance on the item analysis $[F(2.94)=3.32, p=.04]$. The 78-msec difference between conditions $\mathrm{B} 1$ and IB is significant [subjects, $F(2,70)=29.45, p<.001$; items, $F(2,94)=22.9$, $\mathrm{p}<.001]$. Statistically, then, the repetition effects of inflected words on bases are full.

Analysis of the response times to base and derived forms in Experiment 2B gives a similar picture [subjects, $F(2,70)$ $=9.03, \mathrm{p}<.001$; items, $\mathrm{F}(2,94)=8.24, \mathrm{p}<.001]$.

Table 2 also shows the comparable findings on nonwords. Repetition priming among nonwords was statistically absent in both studies [In Experiment 2A, for subjects, $F(2,70)=2.02, p=.14$; for items, $F(2,94)=$ 1.22. In Experiment $2 B$, both $F$ values were less than 1.] Thus, there is no apparent episodic repetition priming on nonwords in these experiments, in which a 48-item lag is used and in which the control procedure for practice is implemented. ${ }^{3}$ (In all subsequent experiments, nonword effects will be reported in tables, but not described in the text unless they involve statistically significant effects.)

\section{Discussion}

Having significantly reduced evidence of episodic priming in nonword stimuli, we obtained a somewhat different picture of repetition priming in derived and inflected words than we obtained in Experiment 1 and than Stanners et al. (1979) reported. In particular, we found that repetition priming of a base form by a derivational relative was as strong as priming by an inflectional relative. Moreover, the priming was statistically (and, in Experiment $2 \mathrm{~B}$, numerically) full.

These findings invite one of two salient interpretations. One, compatible with Butterworth's (1983) assessment of the lexicon, is that repetition priming occurs among separate lexical entries in the lexicon; it is not a consequence (except in the case of exact repetitions) of repeated access to a common lexical entry. The second interpretation is that it does reflect repeated access, but a lexical entry is more inclusive than had previously been suggested by repetition-priming findings. As we will suggest in the General Discussion, the substantive differences between these views are smaller, in light of constraints on their realizations imposed by our findings, than these statements suggest.

In Experiment 3, we further examined the kinds of morphologically related words that are strongly associated, or that share a lexical entry. We did so by examining priming of an unaffixed form by affixed morphological relatives that do not necessarily preserve the spelling or pronunciation of the stem morpheme in its unaffixed form. 
In addition, we examined two types of derivationally affixed words.

Possibly, the derived words we used in Experiment 2 were special and gave rise to unrepresentatively strong priming. Chomsky and Halle (1968) identifed two types of suffixes in English. Neutral affixes include inflections and some derivations; these affixes do not affect pronunciation of the stem morphemes to which they are attached. In contrast, nonneutral (derivational) affixes do affect the stem morpheme's pronunciation (e.g., "sign"-"signal"). In Chomsky and Halle's theory, neutral affixes are separated from the stem morpheme by a word boundary, which prevents application of phonological rules over extents spanning stem and affix. Nonneutral affixes are separated from the stem by lesser morpheme boundaries that do not prohibit application of phonological rules over the whole domain of stem plus affix. In our Experiment 2B, affixes were neutral derivational affixes. Perhaps it is not surprising that neutrally affixed derivations were as effective primes as were inflected words.

In Experiment 3, we compared priming of unaffixed words by morphological relatives that do or do not share pronunciation or spelling of the stem morpheme with the unaffixed form. This allowed us to compare priming by irregular inflected words and regular morphological relatives (cf. Kempley \& Morton, 1982). In addition, in a post hoc analysis, we looked specifically at neutrally and nonneutrally affixed derivations and compared their priming effectiveness.

\section{EXPERIMENT 3}

In Experiment 3, we examined priming by morphologically related forms in which either the pronunciation alone or the spelling and pronunciation of the common morpheme were not shared by prime and target forms. The experiment had two purposes in addition to the one just described (to examine priming by derived forms with nonneutral affixes). A related purpose was to reexamine effects of decreases in formal overlap (and hence, for English, in regularity) between morphologically related primes and targets on repetition priming. Stanners et al. (1979) found that priming of a base by an affixed form decreased as formal overlap between the affixed and unaffixed words decreased. Kempley and Morton (1982) found no priming between irregular and regular forms when the words were presented auditorily. Experiment 3 was designed to reexamine these priming effects under the conditions we developed that reduce episodic priming effects. Possibly, in the earlier studies, the differences in priming across conditions were episodic in origin; targets following formally identical or similar primes cued memory for the primes, whereas dissimilar targets did not. A final purpose of the experiment was to separate effects of orthographic and phonological overlap between prime and target on the magnitude of priming.

\section{Method}

Subjects. Thirty-six students participated in Experiment 3A and 24 different students in Experiment 3B. All came from the same subject pool used in Experiments 1 and 2.

Stimulus materials. Two sets of 24 word triads were devised. In one set, the sound-only set, each triad included one base form and two affixed forms; one affixed form preserved the spelling and pronunciation of the unaffixed form (henceforth the "NC" or "no change"' form) and one preserved only the spelling (henceforth the " $C$ " or "changed" form). An example from this set is "heal," "healer," "health." (In six triads, a silent "e" in the base morpheme was deleted in an affixed form.) The second set, the soundand-spelling set, also consisted of triads including an unaffixed form and two affixed forms. In this set, one affixed word shared both spelling and pronunciation of the base morpheme with the unaffixed word (the NC form for this set), whereas the other affixed word shared neither spelling nor pronunciation with the unaffixed word (the C form). An example from this set is "clear," "clearly," "clarify." In both sets, words in the third category were, with few exceptions, irregular forms.

Because Experiment 2 showed no difference in priming by inflected and derived forms that shared spelling and pronunciation with the unaffixed form, we felt justified in mixing the two types of affixed forms in our new lists. However, approximately equal numbers of derived forms and equal numbers of inflected forms occurred in the sound-only and sound-and-spelling triads, and there were sufficient numbers of pairs of neutrally affixed forms and nonneutrally affixed forms that they could be examined separately in a post-hoc analysis.

Phonological overlap between unaffixed and affixed words was matched across sound-only and sound-and-spelling lists by counting each vowel, consonant, or stress change as one change and matching the number of changes across the two lists. In addition, an effort was made to match type of change (vowel, consonant, or stress) as closely as possible. Our final experiment (Experiment 4B) was an auditory lexical decision experiment using these materials, and showed that our matching efforts were successful.

Unaffixed words in the sound-only and sound-and-spelling lists were matched in length and frequency (Kučra \& Francis, 1967). Similarly, the two different types of affixed forms were matched in length and frequency within and across the two lists. Appendix $C$ lists the word triads in the two stimulus sets.

We created triads of nonwords from triads of words that might have appeared as word stimuli in the experiment. They were made into nonwords by changing one or two letters, while preserving their orthographic regularity. Forty-eight nonword triads were created in this way.

From the sets of words and nonwords, three basic stimulus lists were created. Each base morpheme appeared twice in each list, once as a prime and once as a target. The lists differed in respect to which version of the morpheme (unaffixed, affixed with no sound or spelling change, affixed with a change) appeared as the prime. The target was always the unaffixed form. In each list there were 16 of each type of prime, 8 from the sound-only set and 8 from the soundand-spelling set of stimulus words. There were 16 of each type of nonword prime.

The stimulus lists were organized exactly as in Experiments $2 \mathrm{~A}$ and 2B. As in those experiments, four versions of each basic list were created so that, across subjects, each prime occurred equally often in the first four blocks of stimuli. Each stimulus list was preceded by a practice list of 24 words and 24 nonwords, ordered randomly.

Procedure. The experiment was run twice. The second experiment (3B) was identical to the first (3A) except that the stimuli were presented under degraded viewing conditions (by turning down the contrast on the CRT screen) in an effort to slow response times and thereby, perhaps, magnify the very small departures from full 
repetition priming we observed in Experiment 3A. This manipulation had no effect on the pattern of reaction times we observed; therefore, we present both outcomes together.

The procedure and instructions to the subjects were identical to those used in Experiment 2.

Design. Subjects participated at all levels of the two independent variables, stimulus set (sound-only, sound-and-spelling) and priming condition [B1, BB, NCB ("no-change/base"-i.e., a base primed by an affixed word in which the sound and spelling of the unaffixed base morpheme are preserved), CB ("changed-form/ base" -i.e., a base primed by an affixed word in which the base pronunciation or spelling and pronunciation are changed from the unaffixed version)]. The major dependent measure was response time.

\section{Results $^{1}$}

Extreme response times were deleted from the data, as described for Experiment 1. Results for word and nonword stimuli, collapsed over the factor stimulus set, are presented in Table 3. Separate two-way repeated measures analyses of variance with factors priming condition (B1, $\mathrm{BB}, \mathrm{NCB}, \mathrm{CB}$ ) and stimulus set (sound-only, sound-andspelling) were performed on the outcomes of the two experiments, using subjects as a random effect. Separate item analyses were also run with one within-groups factor (priming condition) and one between-groups factor (stimulus set). In Experiment 3A, the effect of priming condition reached significance in both subject and item analyses [subjects, $F(3,105)=20.82, p<.001$; items, $F(3,138)=12.81, p<.001]$. The effect of stimulus set was significant in the subject analysis, with response times faster in the sound-only condition, but was nonsignificant in the item analysis [subjects, $\mathrm{F}(1,35)=12.59, \mathrm{p}<.001$; items, $F(1,46)=2.44, p=.12]$. The interaction did not approach significance in either analysis (both Fs $<1$ ).

The effect of prime type is due primarily to the difference between the response to an unprimed base (B1) and to a base following any of the three primes [subjects, $F(3,105)=17.75, \mathrm{p}<.001$; items, $\mathrm{F}(3,138)$ $=10.80, \mathrm{p}<.001]$. Among the prime conditions, the difference between the effect of an unaffixed prime (BB) and the effects of the other primes (NCB, CB) reaches significance in the subject analysis, but not in the item analysis [subjects, $\mathrm{F}(3,105)=2.80, \mathrm{p}=.04$; items, $F(3,138)=1.73, p=.16]$. The additional effect of sharing, or not sharing, spelling or pronunciation with

Table 3

Response Times in Experiments $\mathbf{B A}$ and $\mathbf{3 B}$

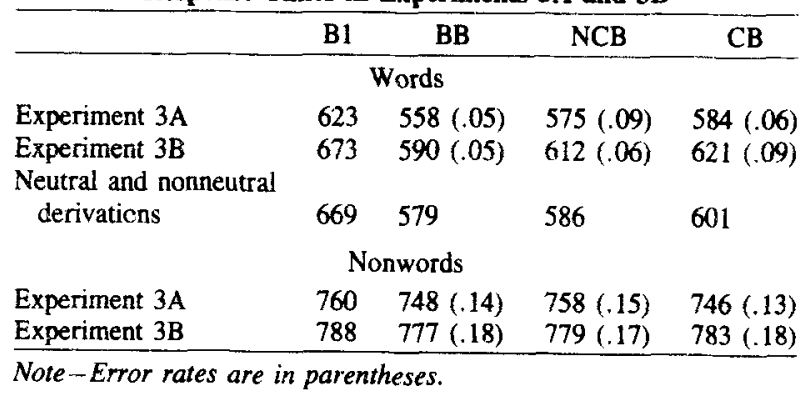

the base (i.e., the difference between 575 and 584) is not significant.

We performed additional analyses on the data of Experiment $3 \mathrm{~A}$ after removing from the sound-only condition the six items in which presence and absence, respectively, of a silent " $e$ " distinguished the base and affixed forms. Removing these items had no effect on the outcome of the experiment. The effect of prime condition remained highly significant; neither the effect of stimulus set nor the interaction was significant.

A major finding of Experiment $3 \mathrm{~A}$ was that priming by affixed forms was nearly full. The priming by NCB forms replicated the outcome of Experiments 2A and 2B. In the present experiment overall, $17 \mathrm{msec}$ less priming occurred when the prime differed from the target in being affixed, but shared sound and spelling with the prime, than when the prime was the unaffixed form itself. CB forms reduced priming by an additional $9 \mathrm{msec}$.

We ran Experiment 3B to determine whether, by slowing response times, we could magnify the small differences we observed between the BB, NCB, and CB conditions. Our manipulation, (reducing the contrast on the CRT screen) slowed response time overall by $42 \mathrm{msec}$. The slowing was significant in an item analysis $[F(1,92)$ $=8.23, \mathrm{p}=.006]$, but not in a subject analysis $[\mathrm{F}(1,58)$ $=2.17, p=.14]$. There were no interactions involving the experiment factor in the overall analysis and, in the analysis of Experiment 3B, there was no increase in the magnitude of the separation of BB and NCB times, on the one hand, or NCB and CB times on the other. Statistical analysis of the response times in Experiment 3B provided a pattern of significant effects identical to the pattern observed in Experiment 3A.

In Experiment 3B, error proportions were $.04, .06$, and .09 on BB, NCB, and CB items, respectively. This was significant [for subjects, $F(2,46)=6.07, p=.005$; for items, $F(2,92)=6.96, p=.002]$.

A final analysis examined neutrally and nonneutrally affixed derivations separately from the irregular inflected forms that were included in the stimulus sets. The purpose of the analysis was to answer the question raised by the finding in Experiment 2 that derivations, as well as inflections, fully primed their base forms. The question raised was whether this finding is limited to neutral affixed derivations, which preserve the pronunciation of the base morpheme.

Eight sound-only and 10 sound-and-spelling triads permitted a comparison of priming by NC neutral affixed derivations and by $C$ nonneutral affixed derivations. These 18 items were subjected to a one-way analysis of variance with the single factor priming condition $(\mathrm{B} 1, \mathrm{BB}, \mathrm{NCB}$, and $C B$ ). The analysis collapsed over the nonsignificant factor, stimulus set, and across Experiments $3 \mathrm{~A}$ and $3 \mathrm{~B}$. Only the item analysis was performed. As Table 3 reveals, the pattern of means mirrors very closely that of the overall analysis. The pattern of significant and nonsignificant differences is also the same as in the overall analysis. Thus, the overall effect of priming condition is signifi- 
cant $[F(3,51)=10.19, p<.001]$. Moreover, the three affixed primes differ from the B1 condition both separately and as a group [overall $F(3,51)=9.70, p<.001$ ]; they do not differ from each other (all Fs less than one). This implies no substantial difference between neutral and nonneutral affixed derivations in their ability to prime an unaffixed morphological relative.

\section{Discussion}

The major finding of Experiment 3 was that there was essentially no loss in repetition priming when the orthographic or phonological representations of affixed primes and morphologicaliy related targets did not fully overlap. Because we found no effect on priming of differences in form between prime and target, we could not separate effects of spelling and sound differences, as we had intended. (We addressed that issue once again in Experiment 4.) We did find a suggestion, significant in the subject analysis only, of a small loss in priming when an affixed prime preceded a base target, as compared with exact repetition priming; but there was no significant additional loss when the affixed form differed in sound or in sound and spelling from the base. This shift, too, was a shift from regular affixed words to largely irregular forms. Thus, we found no loss in priming between regular affixed forms and their irregular morphological relatives. ${ }^{4}$ Accordingly, we concluded that, however repetition priming effects are explained-as repeated access to a common lexical entry, as priming among strongly associated but distinct entries or in some other way-the relationships of irregular and regular, derived, inflected, and unaffixed forms must be explained in fundamentally the same way.

\section{EXPERIMENT 4}

We designed the final experiment with two main purposes in mind. One was to compare priming in the auditory and visual modalities. In Morton's (1981) logogen model, each logogen has paired auditory and visual inputs. That is, a word has a logogen (in the model's most recent version, an "output logogen," but not an "input logogen") in common whether it is auditorily or visually presented. This idea is supported by findings of some cross-modal repetition priming (Kirsner, Milech, \& Standen, 1983). However, whereas in Experiments 3A and $3 B$ we found strong priming of visually presented unaffixed words by irregular morphological relatives, Kempley and Morton (1982) found no priming between auditorily presented unaffixed words and irregular, inflected morphological relatives. Kempley and Morton used stimuli different from ours, and a different paradigm with longer intervals between prime and target. Consequently a variety of reasons for this difference are tenable. In Experiment 4 , we used common word sets and a common paradigm to compare priming in the two modalities directly.
Our second purpose was to examine priming when affixed words appeared as targets in the repetition-priming paradigm. This allowed us to address two questions, one theoretical and one methodological. The theoretical question concerned the organization of morphological relatives in the lexicon. One possibility is that all morphologically related words are uniformly related to each other in the lexicon. Other possibilities can be imagined as well. One may be developed by analogy from a theory of lexical organization in Serbo-Croatian, a highly inflected language (Lukatela, Gligorijevic, Kostic, \& Turvey, 1980). In that so-called "satellite-entries" theory, a particular inflected form (the nominative), rather than the root morpheme, is proposed as the hub of an array of associated morphologically related words (satellites). Inflected words other than the nominative are associated to the nominative form but not (or less strongly) to each other. In this organization, the nominative should prime and be primed by other morphologically related affixed forms more effectively than the affixed forms prime each other. In English, the unaffixed base form is the most likely counterpart to the nominative in Serbo-Croatian. If English has an analogous organization, then the unaffixed word should prime and be primed by affixed forms more effectively than affixed forms prime each other. Our experiment was designed to test for this possibility by examining priming of affixed words by unaffixed and affixed morphological relatives.

The methodological question concerned the possibility that the patterns of priming that we obtained using our paradigm were largely products of a paradigm-specific strategy by which subjects predicted the target given the prime. Forster and Davis (1984) and Oliphant (1983) showed that repetition priming was severely diminished (or absent, in Oliphant's study) if subjects were unaware that words were repeated in the experiment. In the work of Forster and Davis, some subjects were made unaware of the repetitions because the prime was masked. Repetition priming was small, short-lived, and, in at least one respect (absence or presence of a frequency-by-priming interaction), qualitatively different in pattern from priming observed when subjects were aware of the prime.

In other research, one of us (Napps, 1985), also found a reduction in the magnitude of repetition priming when the proportion of targets in the experiment was only .06 of all stimulus items. Even under those conditions, significant priming was found when sound-and-spelling stimuli identical to those of the present Experiment 3 were used out to a lag of 10 intervening items, the longest lag examined by Napps. Napps's findings in this study and in others using low proportions of repeated items suggest that the priming we obtained with a high proportion of related items does not create the appearance of relations among morphological relatives that are unrelated in the lexicon. Rather, they appear to enhance effects of existing relations.

To further address the question of whether our priming reflects lexical organization or, instead, reflects predict- 
ability of the target given the prime, we designed Experiment 4 to reduce the subjects' ability to make useful predictions. In Experiments 1-3, targets were always unaffixed words. Accordingly, given a prime, subjects could guess the identity of the target word that would appear some 50 items later in the next block of stimuli. In Experiment 4 , targets were less predictable than in earlier experiments because each was one of several possible affixed morphological relatives of primes.

As a second assessment of the role of prediction, we provided a separate analysis of repetition priming effects on the very first block of the experiment in which repetitions occurred, (before subjects had an opportunity to develop a strategy of guessing targets from primes). ${ }^{5}$

\section{Method}

Subjects. The subjects were 72 students from the same subject pool as used previously. Thirty-six students participated in each of Experiments 4A and 4B. All subjects in Experiment 4 had normal hearing.

Stimulus materials. The materials were the same as those used in Experiment 3, with one exception. In the test lists, the $\mathrm{NC}$ affixed form replaced the unaffixed form in all positions in which the unaffixed form occurred as a target. This yielded priming conditions NC1 (first occurring affixed item), NCNC (affixed item primed by itself), BNC (affixed item primed by the unaffixed form), CNC (affixed item primed by an affixed morphological item that does not preserve the pronunciation or the spelling and pronunciation of the unaffixed morpheme).

In Experiment 4B, stimulus items were recorded onto audio tape by a female native speaker of English (C.A.F.). These productions were sampled by computer at $10 \mathrm{KHz}$. This enabled the same token of each NC prime or target item to be used in all conditions. The test orders were recorded on one channel of an audio tape. Tone bursts were recorded on the second channel of the tape for the purpose of collecting response times. The tone bursts were synchronized to the onsets of acoustic energy of each stimulus item in the test order. Therefore, response times include word duration (or as much of the word as occurred before the subject made his or her buttonpress response). That stimulus words have different durations is unimportant in the repetition priming procedure, because critical comparisons involve response times made to the same items across different priming conditions. Stimulus items were recorded onto audio tape with a 3-sec interstimulus interval

Only 3 test lists were used in Experiment 4B, whereas 12 were used in Experiments 2, 3, and 4A. The three lists had the same order of stimulus items but differed in respect to which of the three prime types occurred with each target item. It was infeasible to include the additional test orders needed to counterbalance the block in which each stimulus item appeared as prime and target.

Procedure. The procedure for Experiment 4A was identical to that for the previous experiments.

In Experiment 4B, subjects listened over headphones to binaural presentations of the test list. A New England Digital Able 40 minicomputer monitored the second tape channel for the tone bursts and started a millisecond clock when a tone burst was detected. The clock was read and a response and response time were stored when subjects pressed the labeled "word" or "nonword" button on the computer terminal keyboard. If a response was not made within $2.5 \mathrm{sec}$ following stimulus presentation, the computer stopped the tape recorder and printed "Please make a response" on a CRT screen facing the subject. Receipt of the buttonpress response restarted the tape recorder. The tape recorder was also stopped between blocks as subjects received feedback on their mean response times and accuracies for the block. Subjects initiated successive blocks by hitting a key on the terminal keyboard.

Design. In both experiments, subjects participated at all levels of the independent variables, priming condition ( $\mathrm{NC1}, \mathrm{NCNC}$, $\mathrm{BNC}, \mathrm{CNC}$ ) and stimulus set (sound-only, sound-and-spelling). The major dependent measure was response time.

\section{Results ${ }^{1}$}

Errors and extreme response times were eliminated from the analysis, as in the earlier experiments. Table 4 shows the mean response times and errors for Experiments $4 \mathrm{~A}$ and $4 \mathrm{~B}$.

Separate two-way repeated measures analyses of variance were performed on the response times of Experiment $4 \mathrm{~A}$ using subjects and items as random factors. The independent variables were prime condition ( $\mathrm{NC1}$, $\mathrm{NCNC}, \mathrm{BNC}, \mathrm{CNC}$ ) and stimulus set (sound-only, sound and spelling). In both analyses, the effects of prime condition [subjects, $F(3,105)=14.79, p<.001 ;$ items, $\mathrm{F}(3,138)=16.46, \mathrm{p}<.001]$ and the interaction [subjects, $F(3,105)=4.29, \mathrm{p}=.007$; items, $\mathrm{F}(3,138)=$ $3.00, p=.03$ ) were significant. Scheffé's tests performed on the two stimulus sets separately show that, for the sound-only condition, all three primed conditions differ from the unprimed condition and do not differ from each other. For the sound-and-spelling condition, however, whereas the $\mathrm{B}$ and $\mathrm{NC}$ primes were effective, the $\mathrm{C}$ prime did not lead to response times significantly faster than the no-prime condition.

With two exceptions, the results of Experiment 4B were very similar to those of Experiment $4 \mathrm{~A}$. In the analysis of response times to auditorily presented targets, only the effect of prime condition was significant [subjects, $F(3,105)=34.90, p<.001$; items, $F(3,138)=13.46$, $p<.001]$. Neither the main effect of stimulus set nor the interaction approached significance. The nonsignificant interaction contrasts with the finding of Experiment 4A. The absence of an interaction between stimulus set and priming condition with auditory presentation is not surprising in view of the the fact that in Experiment 4A the interaction could be ascribed to the presence or absence of spelling differences between prime and target. The loss of the interaction indicates that we succeeded in matching the stimulus sets along other relevant dimensions.

Scheffé's tests on the effect of prime conditions showed

Table 4

Mean Response Times in Experiments 4A (Visual) and $\mathbf{4 B}$ (Auditory)

\begin{tabular}{llll}
\hline NC1 & NCNC & BNC & CNC \\
\hline Words & &
\end{tabular}

Experiment 4A

Sound only

Sound and spelling

Experiment $4 \mathrm{~B}$

Sound only

$633 \quad 571(.05)$

$585(.04)$

$580(.07)$

Sound and spelling

687

$574(.07)$

$591(.07)$

$646(.08)$

796
807

$734(.09)$

$770(.07)$

$780(.11)$

Experiment 4A

Nonwords

Experiment 4B

$761 \quad 757(.13)$

$771(.14)$

$(.11)$

Note-Error rates are in parentheses. 
that all three primed conditions had shorter response times than the unprimed condition. In addition, however, the exact repetition condition differed significantly from the other priming conditions on both subject and item analyses. This statistically partial priming is the second finding that differs from the findings of Experiment $4 \mathrm{~A}$.

In view of the apparent effect in Experiment $4 \mathrm{~A}$ only of changing spelling between affixed primes and targets, we compared the outcomes of the visual and auditory experiments explicitly. We transformed response times to difference scores by subtracting response times in the $\mathrm{BNC}$ condition from those in the $\mathrm{CNC}$ condition, separately for the sound-only and sound-and-spelling stimulus sets. This provided an estimate of the effects of changing pronunciation alone (sound-only words) and of changing both pronunciation and spelling (sound-andspelling words) between prime and target with both visual and auditory presentation. We performed analyses of variance on the difference scores, with factors experiment and stimulus set. The effect of stimulus set [subjects, $\mathrm{F}(1,70)=4.67, \mathrm{p}=.03$; items, $\mathrm{F}(1,92)=3.49, \mathrm{p}=$ .06 ] and the interaction [subjects, $F(1,70)=4.12, \mathrm{p}=$ .03 ; items, $F(1,92)=3.18, p=.07$ ] were significant in the subject analysis and marginally significant in the item analysis. Planned comparisons on the interaction in the subject analysis showed that the effect of a spelling difference was greater with visual than with auditory presentation $[F(1,70)=5.10, p=.02]$; the difference between the two modalities of presentation on the effect of pronunciation alone (sound only) was nonsignificant $(\mathrm{F}<1)$.

One more analysis of the data from Experiments 4A and $4 \mathrm{~B}$ was performed. To find out whether a subject's ability to guess the target from the prime accounts for priming effects, we examined primes in the first test block and their repeated targets or morphologically related targets in the second block in Experiments $4 \mathrm{~A}$ and $4 \mathrm{~B}$.

In Experiment 4A, across subjects, all items appeared as primes in the first block and as targets in the second. In Experiment 4B, this counterbalancing was infeasible; therefore, just one fourth of the items in each condition appeared as primes in the first block and as targets in the second block.

Restricting our analyses to the primes in the first test block and their targets in the second, in Experiment 4A the effects of priming condition were highly significant in both subject and item analyses [subjects, $F(3,105)=$ $8.89, \mathrm{p}<.001$; items, $\mathrm{F}(3,138)=9.44, \mathrm{p}<.001)$. The effect of stimulus set (sound-only, sound-and-spelling) was significant in the item analysis only; the interaction did not approach significance in either analysis. Means in the four priming conditions ( $\mathrm{NC1}, \mathrm{NCNC}, \mathrm{BNC}$, and $\mathrm{CNC}$ ) were $684,567,607$, and 622 , collapsed over stimulus sets. These times conform closely to means computed over all blocks, presented in Table 4 . A planned comparison of means in the NCl (unprimed) and CNC (primed by an irregular form) conditions was significant [subjects, $\mathrm{F}(1,105)=7.23, \mathrm{p}=.008$; items, $\mathrm{F}(1,138)=7.41$, $\mathrm{p}=.007]$, confirming that priming among regular and irregular affixed forms is present even when subjects are not aware that primes or their morphological relatives will be presented later in the experiment.

The same analyses performed on the first two blocks of trials in Experiment 4B gave essentially the same outcome, that is, the effect of priming condition was significant [subjects, $F(3,105)=11.82, p<.001$; items, $F(3,138)=6.76, p=.001]$. No other factors were significant. Means were 787, 695, 753, and 740 for NC1, NCNC, BNC, and CNC priming conditions, respectively. A planned comparison of the conditions $\mathrm{NCl}$ and $\mathrm{CNC}$ was significant [subjects, $F(1,105)=9.16, p<.001$; items, $F(1,138)=7.98, p=.001]$.

The reaction-time means and the pattern of significant effects in these restricted analyses conform closely to those obtained in the overall analyses. Thus, they confirm that repetition priming in the lexical-decision paradigm does not require a strategy of predicting targets from primes as the primes are presented.

\section{Discussion}

We designed Experiments $4 \mathrm{~A}$ and $4 \mathrm{~B}$ to address three questions. The first was whether the logogen model, with its paired acoustic and visual input logogens, is tenable, particularly in light of our findings in Experiment 3. In Experiment 3, we found that visually presented irregular words do prime their unaffixed relatives fully. In contrast, Kempley and Morton (1982) found that auditorily presented unaffixed words and their irregular inflected relatives do not prime each other. In the present study, we found very similar priming in the two modalities.

The second question was whether we would find evidence of asymmetrical relations among morphological relatives, as researchers have found for Serbo-Croatian (Lukatela et al., 1980). Our experiment failed to support the idea that morphological relatives have a satellite organization, with the unaffixed base word as the center of the satellite. Instead, with one exception, all relationships among morphological relatives appeared strong.

We did obtain one result suggesting both a difference between auditorily and visually presented words in the lexicon and the existence of a satellite organization among orthographically represented words. We found that, with visual presentation, base words are primed essentially fully by affixed morphological relatives not sharing either the spelling or the pronunciation of the shared morpheme (Experiment 3); affixed targets that preserve the spelling and pronunciation of the unaffixed morpheme are not primed fully (Experiment 4A). This loss in priming apparently can be ascribed to the spelling difference between the affixed forms, since an analogous effect was not obtained in the auditory version of the experiment (Experiment 4B). Further evidence will be needed to determine whether this single outcome suggestive of different organizations for phonetic and orthographic forms of words is found reliably.

The final question addressed by Experiments $4 \mathrm{~A}$ and $4 \mathrm{~B}$ was whether our procedure created priming effects by inviting subjects to generate candidate targets when primes were presented. We answered this question in the negative on the basis of two sources of evidence. First, priming occurred over lags of nearly 50 items, even when the target was not highly predictable from the prime. More convincing, perhaps, was the significant priming in the first two blocks of test trials, in which subjects would have no reason to adopt a guessing strategy. These analyses yielded mean response times and patterns of significant effects remarkably similar to those of the overall analyses. In particular, priming, even by irregular forms, remained strong in analyses of both visually and auditorily presented words. Therefore, we ascribe the differences between our results and those of Kempley and Morton (1982) either to differences in the items used or to a longer time lag between prime and 
target in the experiment by Kempley and Morton. The latter appears more likely. Kempley and Morton used inflected forms only, and if there is a difference in strength of priming at all between inflected and derived forms, priming by inflected forms should be stronger.

\section{GENERAL DISCUSSION}

Our major findings can be summarized as follows. We found that losses in priming from full to partial or less, when exact repetition priming is compared with priming by morphological relatives, may be ascribed at least in part to episodic contributions to repetition priming that are larger the more similar the prime and target. By reducing the contribution of these sources of repetition priming, we find strong priming-statistically full, in most cases-among inflected, derived, and unaffixed words, and between regular and irregular words, with either auditory or visual presentation. Accordingly, if repetition priming is interpreted as reflecting lexical organization, as we assume, then our findings disconfirm a theory of lexical organization in which regular inflected forms, but not derived forms or irregular inflections, share a lexical entry with the base. Correspondingly, they disconfirm a theory in which the domain of a lexical entry includes only those words that can be generated by productive, grammatical rules of affixation (see Butterworth, 1983, for a similar conclusion).

Our findings invite either of two extreme interpretations previously contrasted in the literature (e.g., Butterworth, 1983). One is that full repetition priming (after Stanners et al., 1979) or full and partial priming (after Murrell \& Morton, 1974) reflect a lexical entry shared by primes and targets. Therefore, they signal that inflected, derived, regular, and irregular morphological relatives share a lexical entry. This interpretation offers a way of capturing the large differences in longevity that have been found between repetition priming and semantic priming in the literature (see Henderson, 1984). Whereas we have found priming even when nearly 50 items intervene between prime and target, in studies of semantic priming, priming is absent by a lag of 1 or 2 items (Dannenbring \& Briand, 1982; Davelaar \& Coltheart, 1975; Gough, Alford \& Holley-Wilcox, 1981; Meyer, Schvaneveldt, \& Ruddy, 1972; ses also Henderson, 1984, for a direct comparison of semantic and repetition priming).

An unappealing consequence of adopting this interpretation, however, is that the concept of lexical entry is severely weakened. Entries that are as encompassing as our findings imply lack any obvious utility for the language user. The entries cannot serve as input to regular rules of affixation. Indeed, rather than consisting of the stem morpheme, affixed by rule, each entry perhaps must be considered a cluster of tightly associated affixed and unaffixed morphological relatives-a conceptualization not very distinct from the second interpretation we will consider. A second unattractive property of the present in- terpretation is that each entry cannot be associated necessarily with any semantic information at all that is common to words within the domain of the entry (Aronoff, 1976) or to any one syntactic class. Moreover, if the entries are logogens, they do not keep an accurate frequencybased expectancy for all words within the domain of the entry.

An alternative interpretation questions whether semantic and repetition priming are, in fact, qualitatively distinct. Possibly, morphologically related words that prime each other over very long lags are distinct words in the lexicon that are strongly related semantically. If so, there are no grounds for using the priming effects as a basis for inferring sharing of lexical entries. One advantage of this hypothesis is that only one mechanism, not two, is required to account for priming. A second advantage is that language users are not presumed to have lexical entries that encompass syntactically and semantically diverse morphological relatives.

Along with other researchers (e.g., Henderson, 1984; Morton, 1981), however, we are skeptical that morphological priming is exhaustively semantic. For one thing, researchers attempt to use words with the strongest associations or the maximum semantic relatedness when they test for semantic priming; nevertheless, semantic priming does not approach the longevity of repetition priming under comparable conditions. Also, derived words tend to drift semantically after they are coined, so that their meaning is not a simple compositional function of the meaning of the stem plus that of the affix (Aronoff, 1976); therefore, derived words tend to be less semantically related to morphological relatives than are inflected words. However, we obtained equally strong priming from words of both types.

In any case, it may not be necessary to select between the view that repetition priming reflects repeated access to an entry and the view that it reflects associations among words in the lexicon. A third perspective on the lexicon may capture the best features of both of these views. The perspective that we propose is derived from recent network models of the lexicon (e.g., Dell, 1980, 1984; McClelland \& Rumelhart, 1981; Stemberger, 1982), in particular, Dell's model, which is designed to produce speech and, in so doing, to generate natural slips of the tongue. Dell's model provides a more useful source than the more obviously related model by McClelland and Rumelhart (1981), which was designed to generate aspects of word-recognition behavior, because Dell's model includes a required representation of morphological structure. His model has not been extended to orthographic representations of words, but there are no principled barriers to such an extension.

In Dell's network model, the lexicon is a hierarchy of levels of representation including words, morphemes, syllables, syllable constituents, phonemes, and phonetic features. Words such as "swimmer" and "swimming" have distinct word representations (called "nodes"), but 
connect to a common stem-morpheme node and from there to common syllable and phoneme nodes for the shared stem morpheme. Word nodes also have connections to semantic memory, where, presumably, "swimmer" and "swimming" connect to both common and distinct concepts. A word such as "swift" has word, morpheme, and syllable nodes distinct from those of "swimmer,"' but some common phonemes. Finally, a word such as "drown" is unconnected to "swimmer" and its constituents at any level in the lexicon, but shares concepts with it in semantic memory.

The structure of Dell's model is well suited, in general, to explain our pattern of findings. It gives morphological relatives closer ties to each other (other things equal) than to other words in the lexicon; yet it does so without either requiring morphological relatives to share a common word node or treating morphological relations as semantic. Moreover, it can explain why we and others (Stanners et al., 1979; Kempley \& Morton, 1982; Murrell \& Morton, 1974) consistently find numerically or even statistically weaker priming when prime and target are not exactly the same word as when they are.

One difficulty with the model, however, is that it does not allow irregular words such as "heal" and "health" to share a morpheme node as it would have to in order to explain our priming in Experiments 3 and 4. In this model the syllable structure and phonemic constituents of a word are elaborated at hierarchical levels leading from morpheme nodes, thereby requiring that morphemes sharing a node have the same pronunciation. The model could be adjusted by having the syllable level and the levels below it connect directly to the word nodes and not to the morpheme level. Morphological structure, then, would be a hierarchical level independent of levels of phonological structure. This kind of separation may have independent motivation from theories of metrical structure in linguistics (e.g., Selkirk, 1980). However, it remains to be determined whether Dell's model, so modified, would produce natural patterns of speech errors involving morphological structure.

Although the structure of the network model just outlined provides an interesting alternative to the two views of the lexicon usually contrasted in the repetition priming literature, the processing assumptions of a network model cannot handle repetition priming at the lags over which we observed it. In Dell's model, nodes at each hierarchical level are connected by bidirectional excitatory lines of association. Activation of a node is progressively incremented as activation spreads from it to its associated nodes and back again. To prevent every node in the lexicon from being activated eventually, activation of a node is shut down once the relevant unit has been output by the system (in Dell's model, once a phoneme or word has been spoken). For a variety of reasons, activation does tend to rebound after a node's activation has been shut down. This promotes perseveration errors in speech [e.g., from Dell, 1980]: "to the bank to pick up some money" - "to the bank to pick up some bank") and it may explain repetition priming of the magnitude and longevity observed by Forster and Davis (1984) and by Napps (1985) when subjects are unaware of repetitions in the experiment. However, activation lasting for 48 subsequent items (or two days, as Scarborough et al., 1977, have observed) would have disastrous consequences for the model's normal operations. Evidently, priming of the longevity we observed is strategic; possibly, it can be seen in the context of the model as strategic maintenance of activation of a node previously activated by stimulus input. This strategic activation would play no role in ordinary speech and reading, but could be exploited, as in oue experiments, to strengthen repetition priming processes that reveal the organization of words in the lexicon.

\section{REFERENCES}

Aronoff, M. (1976). Word formation in generative grammar. Cambridge, MA: M.I.T. Press.

BERKO, J. (1956). The child's learning of English morphology. Word, 14, 50-77.

Burterworth, B. (1983). Lexical representations. In B. Butterworth (Ed.), Language production, II. London: Academic Press

CHOMSKY, N., \& HALLE, M. (1968). The sound pattem of English. New York: Harper \& Row.

Dannenbring, G., \& Briand, K. (1982). Semantic priming and the word repetition effect in a lexical decision task. Canadian Journal of Psychology, 36, 435-444.

DavelaAr, E., \& Coltheart, M. (1975). Effects of interpolated items on the association effect in lexical decision tasks. Bulletin of the $P_{s y-}$ chonomic Society, 6, 269-272.

DELL, G. (1980). Phonological and lexical encoding in sentence production: An analysis of naturally occurring and experimentally elicited speech errors. Unpublished doctoral dissertation, University of Toronto.

DELL, G. (1984). A spreading activation theory of retrieval in sentence production (Cognitive Science Technical Report). Rochester, NY: University of Rochester.

Feustil, T., Shiffrin, R., \& Salasoo, A. (1983). Episodic and lexical contributions to the repetition effect in word identification. Journal of Experimental Psychology: General, 112, 309-346.

Forbach, G. B., StanNers, R. F., \& HochHaus, L. (1974). Repetition and practice effects in a lexical decision task. Memory \& Cognition, 2, 337-339.

Forster, K., \& DAvis, C. (1984). Repetition priming and frequency attenuation in lexical access. Joumal of Experimental Psychology: Learning, Memory and Cognition, 10, 680-698.

GARRETT, M. (1980a). Levels of processing in sentence production. In B. Butterworth, (Ed.), Language production I. London: Academic Press.

GarRetT, M. (1980b). The limits of accommodation: Arguments for independent processing levels in sentence production. In V. Fromkin (Ed.), Errors in linguistic performance: Slips of the tongue, ear, pen and hand. New York: Academic Press.

Gough, P., Alford, J., \& Holley-Wilcox, P. (1981). Words and context. In O. Tzeng \& H. Singer (Eds.), Perception of print. Hillsdale, NJ: Erlbaum.

Henderson, L. (1984). Morphemic structure and lexical access. In $\mathrm{H}$ Bouma \& D. Bouwhuis (Eds.), Attention and performance, $X$. Hillsdale, NJ: Erlbaum.

JACOBY, L., \& Dallas, M. (1981). On the relationship between autobiographical memory and perceptual learning. Joumal of Experimental Psychology: General, 110, 306-340.

Kempley, S. T., \& MORTon, J. (1982). The effects of priming with regularly and irregularly related words in auditory word recognition. British Journal of Psychology, 73, 441-454. 
Kirsner, K., Milech, D., \& Standen, P. (1983). Common and modality-specific processes in the mental lexicon. Memory \& Cognition, 11, 621-630.

KUČERA, H., \& FRANCIS, W. (1967). Computational analysis of presentday American English. Providence, RI: Brown University Press.

Light, L., \& CARTER-SoBell, L. (1970). Effects of changed semantic context on recognition memory. Journal of Verbal Learning and Verbal Behavior, 9, 1-11.

Lukatela, G., Guigoruevic, B., Kostic, A., \& Turvey, M. T. (1980). Representation of inflected nouns in the internal lexicon. Memory \& Cognition, 8, 415-423.

MCClelland, J., \& Rumelhart, D. (1981). An interactive activation model of context effects in letter perception: Part I. Account of basic findings. Psychological Review, 88, 375-407.

Meyer, D., Schvaneveldt, R., \& Ruddy, M. (1972). Activation of lexical memory. Paper presented at the annual meeting of the Psychonomic Society

Morton, J. (1969). The interaction of information in word recognition. Psychological Review, 76, 165-178.

MorTon, J. (1981). The status of information processing models of language. In H. Longuet-Higgins, J. Lyons, \& D. Broadbent (Eds.), The psychological mechanisms of language. London: The Royal Society and the British Association.

MURRELl, G. A., \& MORTON, J. (1974). Word recognition and morphemic structure. Joumal of Experimental Psychology, 102, 963-968.

NAPPS, S. (1985). Morphological, semantic and formal relations among words and the organization of the mental lexicon. Doctoral dissertation, Dartmouth College.

NAPPS, S., * FowLER, C. (1983). Orthographic organization of lexical forms. Paper presented at the meeting of the Eastern Psychological Association.

NAPPS, S., Fowler, C., \& Feldman, L. (1984). Effects of orthography and phonology on morphological organization of the lexicon. Paper presented at the meeting of the Eastern Psychological Association.

OHALA, J. (1974). Experimental historical phonology. In J. Anderson \& C. Jones (Eds.), Historical linguistics, II: Theoretical description in phonology. Amsterdam: North-Holland.

OLIPHANT, G. (1983). Repetition and recency effects in word recognition. Australian Journal of Psychology, 35, 393-403.

Scarborough, D. L., Cortese, C., \& Scarborough, H. S. (1977). Frequency and repetition effects in lexical memory. Journal of Experimental Psychology: Human Perception and Performance, 3, 1-17.

SELKIRK, L. (1980). The role of prosodic categories in English word stress. Linguistic Inquiry, 11, 563-695.

Stanners, R. F., Neiser, J. J., Hernon, W. P.. \& Hall, R. (1979). Memory representation for morphologically related words. Journal of Verbal Learning and Verbal Behavior, 18, 399-412.

SteinberG, D. (1973). Phonology, reading and Chomsky's optimal orthography. Journal of Psycholinguistics Research, 2, 239-258.

Stemberger, J. (1982). The lexicon in a model of language production. Unpublished doctoral dissertation, University of California, San Diego.

\section{NOTES}

1. The response times we report in this paper differ in absolute value from times reported in Napps and Fowler (1983) and Napps, Fowler, and Feldman (1984). The procedures we used to present stimuli to the computer terminal screen and to collect response times create constant errors. The present response times have been adjusted for those con- stant errors. The times in the earlier presentations were unadjusted. The adjustments do not affect the size in msecs of priming effects.

2. One outcome in Experiment 1 is at apparent odds with the conclusion that some of the priming on words is episodic. We would expect the IB condition to give rise to slightly longer response times than the exact-repetition (BB) condition. A small difference $(7 \mathrm{msec})$ in the appropriate direction does occur in the inflections-and-derivations stimuli, but it is reversed $(-3 \mathrm{msec})$ in the inflections-only stimuli. However, looking across experiments of our own and of others in the literature in which a comparison can be made, in six of eight comparisons IB exceeds BB. The differences are always small and usually nonsignificant. That they are small is not surprising: inflections and base forms are orthographically and phonologically very similar. Moreover, it is possible that an episodic trace in our experiments comprises more lexical information than simply word forms. Much of that additional information would be the same for inflections and base forms.

3. Another assessment of episodic priming in Experiment 2 may be obtained by comparing response times to words in Experiments $2 \mathrm{~A}$ and 2B with corresponding times in Experiment 1 . Although the mean response times may differ across the experiments due to differences in lag, subjects, and, in Experiment 2B, stimulus materials, there would be no loss in episodic priming in the B1 condition of Experiments $2 \mathrm{~A}$ and $2 \mathrm{~B}$ as compared with Experiment 1 , and therefore $\mathrm{B} 1$ response times should be closest across the experiments. For the same reason, DB conditions should show little change when episodic priming is eliminated. The BB and IB conditions should show a relative increase in response time, however. With just one notable exception, the outcomes of Experiments $2 \mathrm{~A}$ and $\mathrm{B}$ were consistent with the predictions. Condition $\mathrm{B} 1$ in Experiments 2A and Conditions B1 and DB in Experiment 2B showed less change from their corresponding times in Experiment 1 than (respectively) Condition IB in Experiment 2A and Condition BB in Experiment $2 \mathrm{~B}$. The exceptional point is the response time to the $\mathrm{BB}$ condition of Experiment 2A, which was $6 \mathrm{msec}$ faster than in Experiment 1, rather than being slower as it should have been. In light of the supportive evidence provided by the other conditions, and, particularly, by the outcome on nonwords, we ascribe this one inconsistency to sampling error or perhaps to a floor on response times in the BB condition of Experiment 1.

4. We should acknowledge, however, that although the difference does not approach significance, irregular forms prime base forms numerically less than do regular forms. More generally in our research using repetition priming, in nearly all instances in which the prime and target are not identical and repetition priming is statistically full, it is numerically less than full. This is the case in most comparisons in Experiments 1-4; similar trends can be seen in the findings of Stanners et al. (1979), Murrell and Morton (1974) and Morton (1981).

5. This analysis assesses priming when subjects have no reason to attempt to predict a future target from a prime. It remains true, however, that by the time the targets are first presented, subjects have been exposed to a large number of morphologically complex words. Possibly, this promotes a tendency to think of morphological relatives of primes. If it does, and thus if the sets of activated relatives can remain activated over lags of $\mathbf{5 0}$ items or more, this finding in itself would be interesting. Moreover, it would most probably require an explanation in terms of activation within the lexicon. Both the capacity and the temporal span of any temporary buffer would be exceeded by the memory demands required to activate a set of morphological relatives for each of the two dozen primes presented within a 48 -item span. In any case, research by Napps (1985) showing repetition priming with very low proportions of morphological relatives, suggests that this cannot be a major source of repetition priming effects. 
APPENDIX A

Experiment 1 Base Words

\begin{tabular}{ll}
\hline enlarge* & replace* \\
yell & gather \\
knead & pick \\
call & adjust* \\
settle* & attain* \\
discern* & laugh \\
sigh & mow \\
retain & rest \\
weld & list \\
gash & govern* \\
walk & equip \\
push & pull \\
punish* & paw \\
agree* & wander \\
toss & develop* \\
talk & deploy \\
enchant & wait \\
spell & enjoy* \\
roll & latch \\
command* & manage* \\
disagree* & blink \\
invent & paint \\
amend & cook \\
pronounce* & detach* \\
\hline
\end{tabular}

*Used with both inflectional and derivational affixes.

APPENDIX B

Experiment 2A and 2B Base Words

\begin{tabular}{llll}
\hline Experiment & 2A & Base Words & \multicolumn{2}{c}{ Experiment } & 2B Base Words \\
\hline enlarge & replace & develop & bright \\
yell & gather & manage & soft \\
knead & pick & govern & eager \\
call & adjust & assess & dark \\
settle & attain & announce & weak \\
discern & laugh & employ & stiff \\
sigh & mow & enjoy & vague \\
retain & rest & punish & complete \\
weld & list & detach & direct \\
gash & govern & disagree & appropriate \\
walk & equip & move & close \\
push & pull & enforce & glad \\
punish & paw & thought & bold \\
agree & wander & fruit & blind \\
toss & develop & help & fond \\
talk & deploy & power & hard \\
enchant & wait & harm & awkward \\
spell & enjoy & care & fresh \\
roll & latch & rest & rich \\
command & manage & color & like \\
disagree & blink & fear & separate \\
invent & paint & use & vivid \\
amend & cook & hope & fair \\
pronounce & detach & thank & polite \\
\hline
\end{tabular}


APPENDIX C

Word Trials Used in Experiments 3 and 4

\begin{tabular}{llllll}
\hline & Sound Only & & & \multicolumn{3}{c}{ Sound and Spelling } \\
\cline { 1 - 2 } Base & No Change & Change & Base & No Change & Change \\
\hline heal & healer & health & creep & creepy & crept \\
sign & signing & signal & defend & defendant & defensive \\
dream & dreamer & dreamt & sleep & sleepy & slept \\
edit & editor & edition & repel & repellent & repulsive \\
deal & dealing & dealt & speak & speaker & spoke \\
reside & resided & residence & decide & decided & decisive \\
produce & producible & productive & assume & assumed & assumption \\
confide & confided & confidence & sweep & sweeping & swept \\
inhibit & inhibiting & inhibition & invade & invader & invasion \\
electric & electrical & electrician & persuade & persuader & persuasive \\
bomb & bomber & bombard & space & spaced & spatial \\
mean & meaning & meant & forget & forgetful & forgotten \\
grade & grading & graduate & sing & singer & sang \\
medic & medical & medicine & fall & falling & fell \\
compare & comparative & comparable & induce & inducement & induction \\
extreme & extremist & extremely & collide & collided & collision \\
create & creative & creature & describe & described & description \\
drive & driver & driven & concede & conceded & concession \\
rise & riser & risen & deep & deeply & depth \\
revise & revising & revision & picture & picturesque & pictorial \\
music & musical & musician & propel & propeller & propulsion \\
lyric & lyrical & lyricism & wise & wisely & wisdom \\
critic & critical & criticize & clear & clearly & clarify \\
clean & cleaner & cleanse & forgive & forgiveness & forgave \\
\hline
\end{tabular}

